\title{
Ein kleiner Frontbummel
}

Erhard Taverna

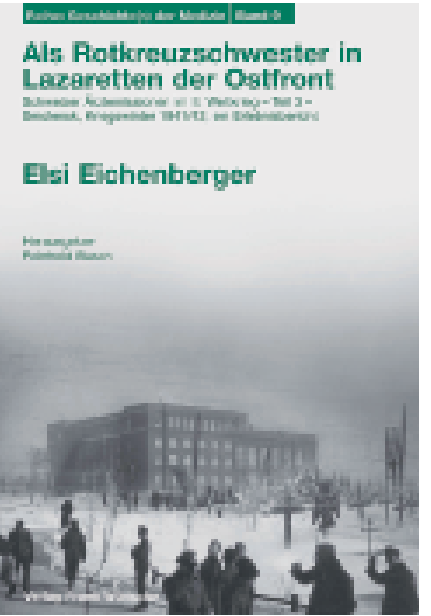

Im Juni 1941 überfielen Hitlers Truppen die Sowjetunion. Bis zur Einkesselung der 6. Armee in Stalingrad im November 1942 war für die verbündeten und neutralen Staaten der Ausgang des Krieges mehr oder weniger ungewiss. Von der scheinbar bevorstehenden Kolonialisierung des Ostens erhoffte sich die europäische Wirtschaftselite grosse Aufträge, unter ihnen auch Schweizer Industrielle, die unter dem Patronat des Roten Kreuzes mehrere Ärztemissionen an die Ostfront finanzierten. Vom Herbst 1941 bis zum Frühling 1943 wurden 250 Schweizer Ärzte, Krankenschwestern und technisches Personal unter der Leitung des Chirurgen Oberstdivisionär Eugen Bircher viermal ausschliesslich in Frontlazaretten der deutschen Wehrmacht eingesetzt.

Die 1912 geborene Krankenschwester Elsi Eichenberger, die sich an zwei von vier Einsätzen beteiligte, veröffentlichte kurz nach Kriegsende ihren Erlebnisbericht aus der weitgehend zerstörten Frontstadt Smolensk. Das vorliegende Buch ist ein Nachdruck ihrer Tagebücher, ergänzt mit vielen Fotografien und mit Berichten noch lebender Augenzeugen. Das Buch schildert eindrücklich die Hinreise über Berlin, den Alltag im Kriegswinter 1941/42 und die bereits erschwerte Rückreise in die unversehrte Heimat. Noch herrscht am Wannsee Optimismus: «So, kommen Sie zu unserm Sieg?» meint lächelnd unser elegant aussehender Betreuungsoffizier. «Moskau fällt in den nächsten Tagen. Es wird eine Studienreise für Sie werden, ein kleiner Frontbummel.» Die Realität ist aber unübersehbar eine andere. Die kluge Autorin beobachtet präzis den Gemütszustand der verwundeten Soldaten und wird immer wieder Zeugin der an gefangenen Russen und Juden verübten Grausamkeiten. Ihre Aufzeichnungen verraten aber auch viel über ihren eigenen, naiven Idealismus, den ihrer Begleiter und den Charakter der deutschen Sanitäts- und Wachtmannschaften. Schon bald nach der Abreise vergeht ihr das Singen, zuviel ist aus dem Coupéfenster sichtbar geworden, wo Erschossene am Bahndamm liegen und vollgepferchte Güterwaggons mit Gefangenen kreuzen. Dem Vorgesetzten der Delegation passt das nicht: «Wer sagt, dass ihr nicht singen sollt?» ruft Oberstdivisionär Bircher dazwischen. «Habt ihr das Soldatenleben noch immer nicht erfasst? Soldatenleben und das heisst lustig sein», so lange ihr es könnt. Aufheitern, helfen, lächeln, sich einsetzen, zupacken, der Gegenwart leben, das heisst Soldat sein! Deshalb ist die Erziehung zur Härte das einzig Richtige und Notwendige. Sie allein ist imstande, der Kriegspsychose trotzend $\mathrm{zu}$ begegnen. Das will man mir in der Heimat nicht glauben, wie so vieles andere auch nicht. Aber ob man's glaubt oder nicht, versteht oder nicht, Härte muss sein.»

Beim Abschied in Bern intonierte ein Regimentsspiel «Rufst du, mein Vaterland», bei der Rückkehr war ausser den Familienmitgliedern kein Mensch zugegen. Von den rund 100 Teilnehmern der ersten Mission schrieben mehrere über ihre dreimonatige Erfahrung in und um Smolensk. Ihre schockierenden Berichte und Fotografien interessierte die Alliierten mehr als den Bundesrat. Der beeilte sich, mit einem öffentlichen Dementi die Zeugenaussagen zu beschönigen und erteilte ihnen ein Rede- und Schreibverbot. Dokumente über Kriegsverbrechen in Warschau kamen unter Verschluss. Im gleichen Jahr wurde die Grenze für jüdische Flüchtlinge geschlossen. Alle Ärzte und Krankenschwestern, die Gesundheit und Leben riskierten, wurden mehrfach betrogen: zuerst mit falschen Vorgaben vom Roten Kreuz und danach von den eigenen Behörden, die sie, je nach politischer Lage, zuerst mundtot machten oder bei Bedarf der Kollaboration mit den Nazis bezichtigten.

Elsi Eichenberger zog sich ins Privatleben zurück und arbeitete nach dem Krieg als Haushilfe und Gemeindeschwester.

Elsi Eichenberger. Als Rotkreuzschwester in Lazaretten der Ostfront. Herausgeber Reinhold Busch. 2. überarbeitete Auflage. Berlin: Verlag Frank Wünsche; 2004. 312 Seiten. 